\title{
BMJ Open Cross-sectional evaluation of the relationship between vitamin $D$ status and supplement use across levels of kidney function in adults
}

\author{
Linda W Moore, ${ }^{1,2}$ Wadi N Suki, ${ }^{3}$ Keri E Lunsford, ${ }^{1,4}$ Omaima M Sabek, ${ }^{1,4}$ \\ Richard J Knight, ${ }^{1,4}$ A Osama Gaber ${ }^{1,4}$
}

To cite: Moore LW, Suki WN, Lunsford KE, et al. Crosssectional evaluation of the relationship between vitamin D status and supplement use across levels of kidney function in adults. BMJ Open 2019;9:e022471. doi:10.1136/ bmjopen-2018-022471

- Prepublication history and additional material for this paper are available online. To view these files, please visit the journal online (http://dx.doi org/10.1136/bmjopen-2018022471).

Received 23 February 2018 Revised 16 0ctober 2018 Accepted 19 0ctober 2018

Check for updates

(c) Author(s) (or their employer(s)) 2019. Re-use permitted under CC BY-NC. No commercial re-use. See rights and permissions. Published by BMJ.

${ }^{1}$ Department of Surgery, Houston Methodist Hospital, Houston, Texas, USA

${ }^{2}$ Center for Outcomes Research, Houston Methodist Research Institute, Houston, TX, USA

${ }^{3}$ Department of Medicine, Houston Methodist Hospital, Houston, Texas, USA

${ }^{4}$ Department of Surgery, Weill Cornell Medical College, Houston, Texas, USA

Correspondence to Dr Linda W Moore; LWMoore@houstonmethodist. org

\section{ABSTRACT}

Objectives The objective of this study was to assess vitamin D status of US non-pregnant adults using a standardised assay across $15 \mathrm{~mL} / \mathrm{min} / 1.73 \mathrm{~m}^{2}$ increments of kidney function, report the use of dietary supplements containing vitamin $\mathrm{D}$ and assess relationships between vitamin $\mathrm{D}$ and markers of bone resorption.

Design This study is a cross-sectional evaluation. Setting The study is from the US National Health and Nutrition Evaluation Survey in 2001-2012.

Participants The participants were non-institutionalised, non-pregnant adults, age $\geq 20$ years.

Primary and secondary outcome measures The primary outcome measure was serum $250 \mathrm{HD}$ evaluated using liquid chromatography-tandem mass spectroscopy traceable to international reference standards. Secondary outcome measures were use of dietary supplements containing vitamin $D$ and the serum intact parathyroid hormone and bone-specific alkaline phosphatase in a subset of participants.

Results The median 250HD concentration in 27543 US non-pregnant adults was $25.7 \mathrm{ng} / \mathrm{mL}$ (range, 2.2-150.0 ng/ $\mathrm{mL})$. Vitamin D supplements were used by $38.0 \%$; mean $(\mathrm{SE})=757$ (43) international units/day. The range of 250HD concentration across groups, stratified by kidney function, was $23.0-28.1 \mathrm{ng} / \mathrm{mL}$. The lowest concentration of $250 \mathrm{HD}$ observed was in people with higher kidney function $(23.0 \mathrm{ng} / \mathrm{mL}$ for estimated glomerular filtration rate $>105 \mathrm{~mL} / \mathrm{min} / 1.73 \mathrm{~m}^{2}$ ). Only $24 \%$ of people not taking a dietary supplement had a $250 \mathrm{HD}$ concentration $>30 \mathrm{ng} / \mathrm{mL}$. Serum intact parathyroid hormone inversely correlated with $250 \mathrm{HD}$ within all kidney function groups. Bone-specific alkaline phosphatase was also negatively associated with $250 \mathrm{HD}$ concentration.

Conclusions These data indicate that $250 \mathrm{HD}$

concentrations and supplement use may be suboptimal in a significant proportion of the population, across all kidney function levels. The response of bone resorption markers further suggests that 250HD levels could be improved. Together, these data support a re-evaluation of the $250 \mathrm{HD}$ concentration associated with health in adults.

\section{INTRODUCTION}

Research over the past 15 years has highlighted the importance of vitamin $\mathrm{D}$ in
Strengths and limitations of this study

- Data were from the US National Health and Nutrition Examination Survey over the 12-year period 2001 to 2012, released in October 2017.

- Participants in the northern region were surveyed in May to October while participants in the southern region were surveyed in November to April.

- Only non-pregnant adults $\geq 20$ years of age were included.

- Vitamin D was assessed as 250HD using liquid chromatography, tandem mass spectroscopy, traceable to international reference standards.

- Limitations are the cross-sectional study limits applicability regarding causation and bone resorption markers were not available for each cycle.

multiple medical conditions and disease states, leading to a developing interest in basal serum vitamin $\mathrm{D}$ concentrations of adults, measured as 25-hydroxycholecalciferol (calcidiol or 25OHD). Season, latitude and ethnicity are important considerations when evaluating $25 \mathrm{OHD}$ status. A high prevalence of insufficiency has been demonstrated in adults around the world, ${ }^{1-3}$ including the USA. $^{4}$

The interpretation of 'deficiency' in these reports $^{1-4}$ is based on concentrations of $25 \mathrm{OHD}$ that are associated with a higher risk of bone fractures. The National Academy of Medicine (NAM, formerly the Institute of Medicine) has recommended allowances of vitamin D (from dietary intake or supplementation) for US adults at 600 international units (IU), or 800 IU for adults $>70$ years, based on the amount of vitamin $\mathrm{D}$ required to achieve a concentration of at least $20 \mathrm{ng} /$ $\mathrm{mL}$ in almost everyone. ${ }^{56}$ However, others have recommended concentrations of $25 \mathrm{OHD}>30 \mathrm{ng} / \mathrm{mL}$ to support the functions of vitamin $\mathrm{D}$ beyond bone health. ${ }^{7-10}$ 
Although the influence of vitamin $\mathrm{D}$ on bone is the main and most widely studied role, vitamin $\mathrm{D}$ also exhibits a variety of non-skeletal or non-calcemic functions. ${ }^{5}$ 7-10 Low 25OHD concentrations are associated with increased risk of infection, autoimmune disease, cancer (especially colon cancer), muscle weakness, diabetes mellitus and cardiovascular disease. ${ }^{7911}$ Stronger evidence is necessary to better understand these associations.

Both kidney disease and obesity/insulin resistance are associated with lower vitamin D concentration. ${ }^{12}$ Vitamin D metabolism is altered by kidney dysfunction, which interrupts the nephrological hydroxylation of 25OHD, resulting in lower levels of $1,25(\mathrm{OH})_{2} \mathrm{D}_{3}$, the active hormonal form of vitamin D. ${ }^{13}$ 25OHD is also rarely sufficient in patients with chronic kidney disease (CKD), particularly patients with severely depressed kidney function. ${ }^{1415}$ The decline in 25OHD concentration appears to occur when glomerular filtration rate (GFR) falls below $80 \mathrm{~mL} / \mathrm{min} / 1.73 \mathrm{~m}^{2} .{ }^{15}{ }^{16}$ Low serum $25 \mathrm{OHD}$ decreases the availability of $25 \mathrm{OHD}$ in the kidney for $1 \alpha$-hydroxylase conversion to $1,25-(\mathrm{OH})_{2} \mathrm{D}$ at any level of kidney function. ${ }^{13}{ }^{17-19}$ Additionally, whether vitamin D sequesters in adipose tissue ${ }^{2021}$ or is diluted in relationship to an increased tissue mass, ${ }^{22}$ serum 25 OHD levels are markedly decreased in the setting of obesity. Thus, the high proportion of overweight and obesity in the USA contributes to the prevalence of deficiency and insufficiency of serum $25 \mathrm{OHD} .^{23}$

Variability in assays used across previously published studies further complicates understanding of vitamin D in populations. A good assay of vitamin D should appropriately uncouple vitamin $\mathrm{D}$ from its binding proteins and overcome matrix effects of the sample environment (eg, uraemia, low vitamin D binding protein) for an accurate measurement. ${ }^{24}$ For example, the variability of vitamin $\mathrm{D}$ results across races have been associated with race-related differences in vitamin $\mathrm{D}$ binding protein. ${ }^{25} 26$ Immunoassays, like the radioimmunoassay (RIA) used in the National Health and Nutrition Examination Survey (NHANES) from 2001 to 2006, are less reliable for detecting the true vitamin $\mathrm{D}$ concentration when the matrix is compromised, as occurs in uraemia. The preferred vitamin D assay should be consistently accurate, precise and specific and use internationally approved reference standards. In 2010, a committee was formed to devise a solution to the vitamin $\mathrm{D}$ assay variability. ${ }^{27}$ Inconsistencies, such as shifts and drifts, between RIA kits for 25OHD have been noted since 2001. ${ }^{28}$ All but one $^{3}$ report previously mentioned ${ }^{1-48-10}$ as identifying the prevalence of vitamin D deficiency used assays with more than currently acceptable variability. The Centres for Disease Control and Prevention (CDC) has recently adopted the liquid chromatography-tandem mass spectroscopy (LC-MS/MS) assay standardised to international reference standards for use in NHANES. ${ }^{27}{ }^{28}$ To date, however, 25OHD status across kidney function levels has not been reported using standardised assay methods.
Therefore, this study aimed to examine the 25OHD status of US non-pregnant adults measured by LC-MS/ MS while accounting for the level of kidney function and dietary supplement use, and to characterise the relationship of vitamin $\mathrm{D}$ with other biological markers available in NHANES in 2001-2012.

\section{MATERIALS AND METHODS}

NHANES uses a complex, multistage probability sampling strategy to collect health data of US residents using 2-year sequences or cycles. Data from Southern residents are collected from November through April and from Northern residents from May through October. The data for this study were collected in six 2-year cycles (2001-2012) with vitamin D data released in October 2015 for the 2001-2010 cycles and in October 2017 for the 2011-2012 cycles. The study population consists of adults (age $\geq 20$ years) who completed both the interview and the physical/laboratory examination components. Pregnant women were excluded. NHANES was approved by the National Centre for Health Services Research Ethical Review Board of the US Department of Health and Human Services. All participants provided written informed consent prior to study procedures.

\section{Laboratory assessments}

Serum creatinine was analysed by the isotope dilution mass spectrometry-traceable Synchron LX Creatinine Reagent kit (Beckman Coulter, Brea, California, USA; reference $0.7-1.3 \mathrm{mg} / \mathrm{dL}$ for men and $0.6-1.1 \mathrm{mg} / \mathrm{dL}$ for women) by Collaborative Laboratory Services, LLC (Ottumwa, Iowa, USA).

In 2001-2006, the Diasorin RIA method was used to measure 25OHD. From 2007 to 2012, measurements of 25OHD were performed using the LC-MS/ MS assay, traceable to international reference standards. A bridging study using stored specimens from 2001 to 2006, previously described, ${ }^{28}$ provided regression equations for applying the conversion of the RIA method to the LC-MS/MS assay for 2001-2006 ( $\mathrm{r}=0.99)$. Vitamin $\mathrm{D}$ was measured as $25 \mathrm{OHD}(\mathrm{ng} / \mathrm{mL})$ at the Fat Soluble Nutrients Laboratory (CDC, Atlanta, Georgia, USA). The laboratory reference cut-points for the LC-MS/MS assay is $<12 \mathrm{ng} / \mathrm{mL}, 12-20 \mathrm{ng} / \mathrm{mL},>20 \mathrm{ng} / \mathrm{mL}$ and $>50 \mathrm{ng} /$ $\mathrm{mL}{ }^{5}$

Parathyroid hormone was measured as intact parathyroid hormone (iPTH, reference $18-74 \mathrm{pg} / \mathrm{mL}$ ) using the ECL/Origen-electrochemiluminescence, Elecysy 1010 analyser (Roche, Basel, Switzerland) at Harborview Medical Centre, University of Washington (Seattle, Washington, USA).$^{29}$ Bone-specific alkaline phosphatase (BAP) was analysed using the Access Octase assay (Beckman Coulter, Fullerton, California, USA), on the Beckman Access at University of Washington (Seattle, Washington, USA) ${ }^{30}$ (reference $3.7-20.0 \mu \mathrm{g} / \mathrm{L}$ for men and $2.9-14.5 \mu \mathrm{g} / \mathrm{L}$ for premenopausal women). No participants $>49$ years received BAP assessment. 


\section{Clinical assessments}

Kidney function was assessed as estimated GFR (eGFR) using the Chronic Kidney Disease Epidemiology Consortium equation (CKD-Epi) and reported in increments of $15 \mathrm{~mL} / \mathrm{min} / 1.73 \mathrm{~m}^{2}$ according to the recommendations of the Kidney Disease Improving Global Outcomes practice guidelines. ${ }^{3132}$ NHANES data set has only one value of serum creatinine rather than multiple values over 3 months; therefore, chronicity of kidney disease cannot be assumed from these data. However, even acute reductions in eGFR increase the risk for kidney disease, drug toxicities, metabolic complications, cardiovascular disease and mortality. ${ }^{32}$ Thus, the appropriate handling of an assessment of kidney function from cross-sectional data sets is to report the spectrum of kidney function without inferring chronicity. ${ }^{32}$

For the purpose of this report, vitamin D sufficiency was defined as serum $25 \mathrm{OHD}$ concentration $>30 \mathrm{ng} / \mathrm{mL}$, insufficiency as 20 to $30 \mathrm{ng} / \mathrm{mL}$ and deficiency as $<20 \mathrm{ng} /$ mL. ${ }^{1033}$

The use of vitamin supplements during the previous 30 days containing vitamin $\mathrm{D}$ was examined. The type of supplement (single component, multivitamin with minerals) was recorded and the amount of the nutrient in the supplement was assessed.

Socioeconomic status was assessed as education level and family income level. Education was less than a high school diploma, high school graduate or general education development test equivalent, some college or Associate of Arts degree, or college graduate or above. Annual family income was $<$ US $\$ 20000$; $\$$ US20 000 to $<$ US $\$ 45000$; US $\$ 45000$ to $<$ US $\$ 75000$ or $\geq$ US $\$ 75000$.

iPTH was assessed only during 2003-2006. BAP was assessed in a subset of participants $<50$ years of age during 2001-2004. For comparisons with iPTH, only 2003-2004 data could be used. Demographic and clinical characteristics of the iPTH and BAP subsets are provided in online supplementary tables 1 and 2 .

\section{Patient involvement}

NHANES is designed by the National Centre for Health Statistics of the CDC of the US Department of Health and Human Services. Participants are volunteers but are not invited to input study design. Participants are made aware of the study results through publication.

\section{Statistical analysis}

Complex survey statistics were evaluated using SAS Survey (SAS V.9.2, SAS Institute, Cary, North Carolina, USA) with appropriate weighting. Least squares mean (SE) for vitamin $\mathrm{D}$ and $\mathrm{iPTH}$ were determined across all kidney function groups and compared using one-way analysis of variance with Bonferroni correction. Wald log-linear $\chi^{2}$ was used to compare categorical variables across kidney function groups. Non-linear regression demonstrated the relationship of $25 \mathrm{OHD}$ to $\mathrm{iPTH}$, by choosing a model showing the lowest Akaike information criterion and Bayesian information criterion (linear, logarithmic, power or S-curve). For comparisons using BAP, due to using only a single 2-year cycle in adults 20 to 49 years of age, a simple random sample analysis was conducted. No imputation of missing data was performed because the missing data represented $<10 \%$ of the potential participants. $^{34}$

\section{RESULTS}

During the 2001-2012 period of the NHANES, a total of 61951 US non-institutionalised residents were surveyed (see online supplementary figure 1). After excluding pregnancy, a total of 30232 participants $\geq 20$ years of age completed both the interview and medical examination components. Additional exclusions comprised 2689 who did not have a serum 250HD level or a serum creatinine for kidney function assessment. A comparison of evaluable and non-evaluable cases demonstrated that $8.9 \%$ of US non-pregnant adults were non-evaluable for the question (see online supplementary table 3 ). Thus, the final sample population was 27543 non-pregnant US adults (see online supplementary figure 1).

Demographic and clinical characteristics of the US non-pregnant adult population demonstrated the diverse socioeconomic strata and proportion of obesity, hypertension and hyperglycaemia (table 1) similar to what has been reported elsewhere. ${ }^{23}$ As expected, participants with low GFR were significantly more likely to be older, men, have hypertension and diabetes and to be of lower education level and socioeconomic status. The presence of obesity, however, was consistent across kidney function level groups.

\section{Vitamin D concentration and supplement use}

The mean (SE) 25OHD concentration was 26.2 (0.2) ng/ $\mathrm{mL}$ and ranged from 2.2 to $105.2 \mathrm{ng} / \mathrm{mL}$ (table 2) with a median of $25.7 \mathrm{ng} / \mathrm{mL}$ (see online supplementary table 4 ); fewer than $30 \%$ had a $25 \mathrm{OHD}>30 \mathrm{ng} / \mathrm{mL}$. NAM reference range of vitamin $\mathrm{D}$ of $>20 \mathrm{ng} / \mathrm{mL}$ for bone health was met by $72.1 \%$ of the participants (see online supplementary table 5) and $27.9 \%$ demonstrated vitamin D insufficiency $(<20 \mathrm{ng} / \mathrm{mL})$.

Vitamin D supplement use was reported by $38.0 \%$ of study participants ( $\mathrm{n}=9522$; table 2 and online supplementary table 5) with an overall mean (SE) of $757^{35}$ IU per day. Only $24.0 \%(n=3179)$ of participants not taking a vitamin D supplement had a 25OHD concentration >30 ng/ $\mathrm{mL}$ while $36.1 \%(\mathrm{n}=8194)$ had serum $25 \mathrm{OHD}<20 \mathrm{ng} /$ $\mathrm{mL}$ and $8.8 \%(\mathrm{n}=2239)$ had serum $25 \mathrm{OHD}<12 \mathrm{ng} / \mathrm{mL}$ (online supplementary table 5). Of those in the highest vitamin D supplement group $(\geq 800 \mathrm{IU} / \mathrm{d})$, only $6.7 \%$ $(\mathrm{n}=197)$ had serum $250 \mathrm{OHD}<20 \mathrm{ng} / \mathrm{mL}$.

\section{Vitamin D concentration and supplement use stratified by kidney function}

The mean 25OHD concentration among kidney function level groups ranged from 23.0 to $28.1 \mathrm{ng} / \mathrm{mL}$, with no apparent relationship to the degree of kidney dysfunction 


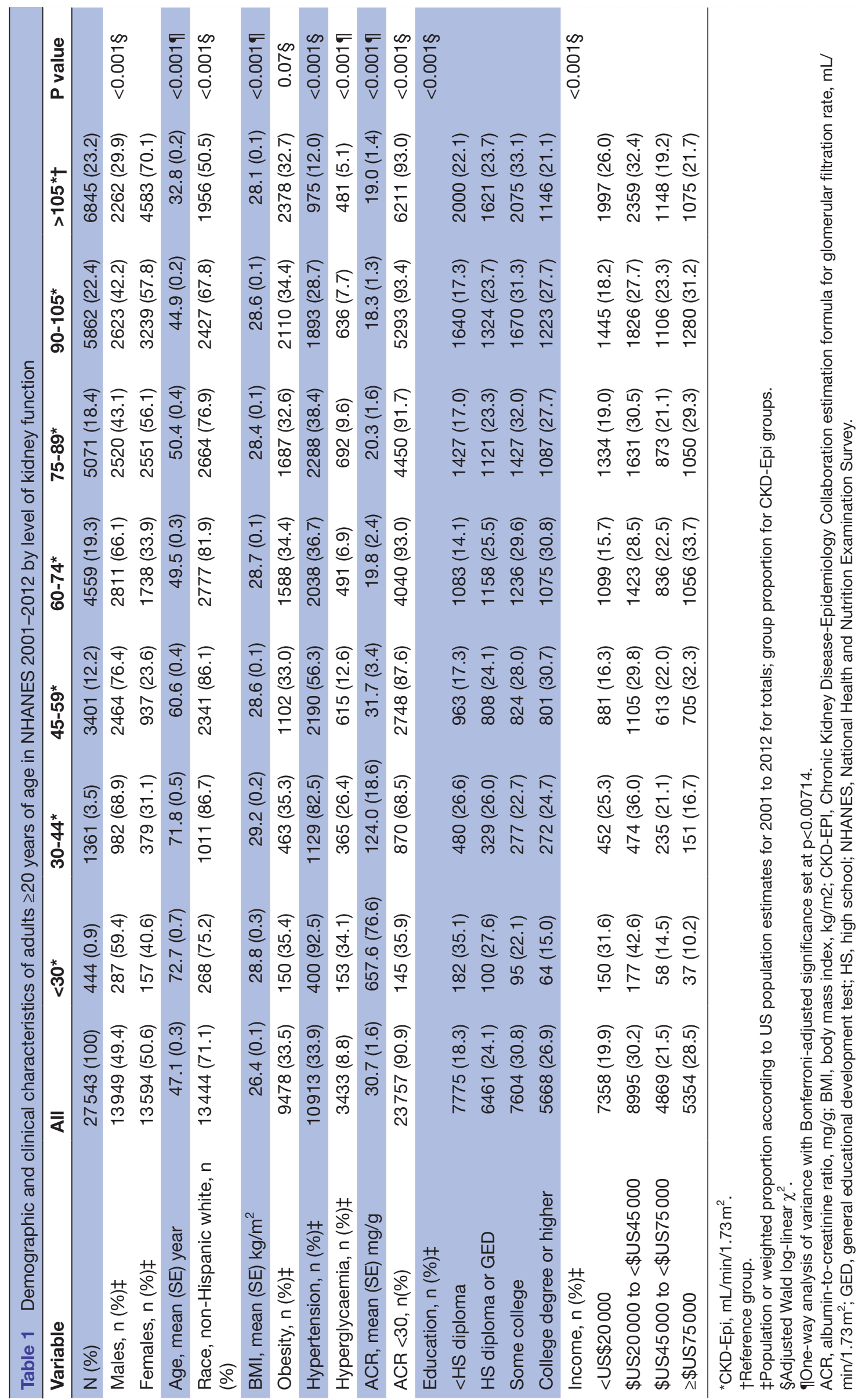


Table 2 Mean vitamin D concentration and proportion of participants taking vitamin D supplements according to kidney function level and dietary vitamin D supplement groups in NHANES 2001-2012

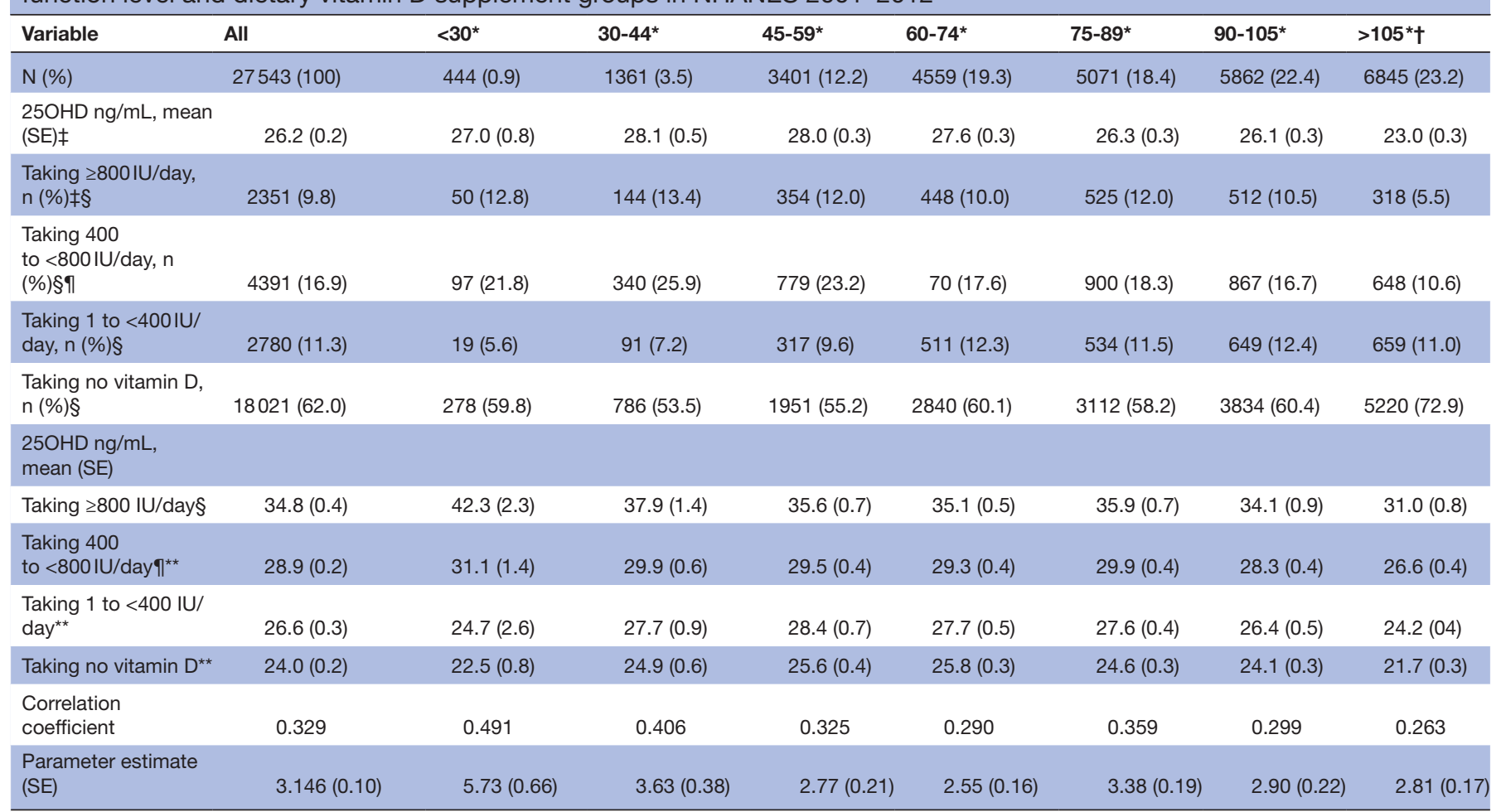

SI conversion factors: to convert $25 \mathrm{OHD}$ to $\mathrm{nmol} / \mathrm{L}$, multiply values by 2.5 .

${ }^{*}$ CKD-Epi, $\mathrm{mL} / \mathrm{min} / 1.73 \mathrm{~m}^{2}$.

†Reference group.

$\ddagger$ Wald log-linear $\chi^{2}, \mathrm{p}<0.001$.

§Population or weighted proportion according to US population estimates for 2001 to 2012 for totals, group proportion for CKD-Epi groups.

१Domain regression analysis (vitamin D supplement group) for serum $250 \mathrm{HD}$ concentration (dependent variable) and kidney function level group (independent variable), all $P$-values $<0.001$.

${ }^{* *}$ Reference group.

CKD-Epi, Chronic Kidney Disease-Epidemiology Collaboration estimation formula for glomerular filtration rate; IU, international units; NHANES, National Health and Nutrition Examination Survey.

(table 2). The lowest mean value of serum 25OHD was noted among participants with eGFR $>105 \mathrm{~mL} /$ $\min / 1.73 \mathrm{~m}^{2}$. Overall, the lowest $25 \mathrm{OHD}$ concentration occurred in adults with kidney function $\geq 75 \mathrm{~mL} /$ $\min / 1.73 \mathrm{~m}^{2}$, representing $64 \%$ of the US non-pregnant adult population. In all kidney function groups, participants taking vitamin D supplements had significantly higher vitamin $\mathrm{D}$ concentration than those not taking supplements $(p<0.001)$, but none demonstrated mean vitamin D levels within the sufficient range (>30 ng/ $\mathrm{mL}$ ) without oral supplementation, at any level of kidney function (see online supplementary table 6). The lowest proportion of participants considered vitamin D sufficient had eGFR $>105 \mathrm{~mL} / \mathrm{min} / 1.73 \mathrm{~m}^{2}$ (figure 1 and online supplementary table 7) followed by participants with eGFR $90-105 \mathrm{~mL} / \mathrm{min} / 1.73 \mathrm{~m}^{2}$.

\section{Relationship of serum iPTH to serum vitamin D}

In US non-pregnant adults evaluated in NHANES 20032006, iPTH was highest in participants with a vitamin D concentration $<20 \mathrm{ng} / \mathrm{mL}$ and was lowest in those with vitamin D concentrations $>30 \mathrm{ng} / \mathrm{mL}$ (figure 2 and online supplementary table 7 ). This observation was consistent at each kidney function level. The iPTH concentration progressively increased as the measured 25OHD concentration decreased. The non-linear relationship (figure 3 and online supplementary table 8 ) of 25OHD and iPTH demonstrates an increased iPTH at 25OHD concentrations $<40 \mathrm{ng} / \mathrm{mL}$ at each kidney function level. The

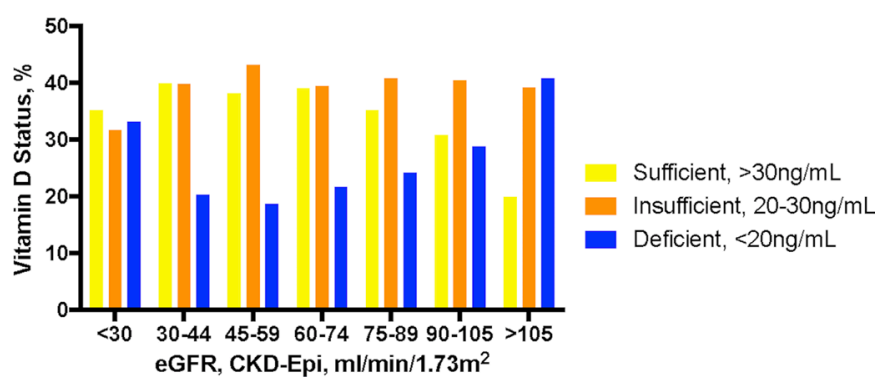

Figure 1 Vitamin D status according to level of kidney function in adults from the National Health and Nutrition Examination Survey 2001-2012. CKD-Epi, Chronic Kidney Disease-Epidemiology Collaboration estimation formula for glomerular filtration rate; eGFR, estimated glomerular filtration rate. 


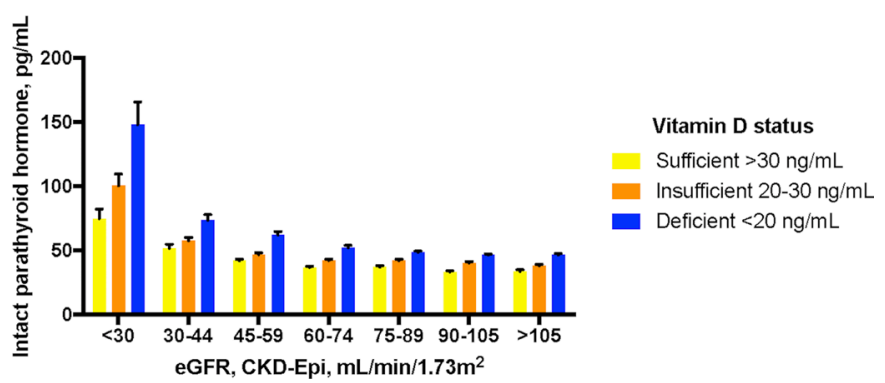

Figure 2 Serum intact parathyroid hormone concentration according to vitamin D status and level of kidney function in adults from the National Health and Nutrition Examination Survey 2003-2006. CKD-Epi, Chronic Kidney DiseaseEpidemiology Collaboration estimation formula for glomerular filtration rate; eGFR, estimated glomerular filtration rate.

relationship rises more steeply for CKD-Epi $<75 \mathrm{~mL} /$ $\mathrm{min} / 1.73 \mathrm{~m}^{2}$ at $25 \mathrm{OHD}<30 \mathrm{ng} / \mathrm{mL}$.

\section{Relationship of serum iPTH and serum vitamin D to serum bone-specific alkaline phosphatase}

Subgroup analysis of BAP demonstrated significant correlations with serum iPTH and 25OHD concentrations. For iPTH, a positive relationship with BAP occurred in participants with eGFR $\geq 60 \mathrm{~mL} / \mathrm{min} / 1.73 \mathrm{~m}^{2}(\mathrm{r}=0.16$, Parameter estimate $(\mathrm{PE})=0.53 \quad(0.001), \mathrm{p}=<0.001)$ but was stronger in those with eGFR $<60 \mathrm{~mL} / \mathrm{min} / 1.73 \mathrm{~m}^{2}$ $(\mathrm{r}=0.49, \mathrm{PE}=4.00 \quad(0.003), \mathrm{p}=<0.001)$. In contrast, the relationship between BAP and 25OHD was negative at eGFR $\geq 60 \mathrm{~mL} / \mathrm{min} / 1.73 \mathrm{~m}^{2}, \mathrm{r}=-0.14, \mathrm{PE}=-0.235(0.001)$, $\mathrm{p}<0.001$; and stronger at eGFR $<60 \mathrm{~mL} / \mathrm{min} / 1.73 \mathrm{~m}^{2}$, $\mathrm{r}=-0.29, \mathrm{PE}=-0.535(0.001), \mathrm{p}<0.001$.

\section{DISCUSSION}

Due to variations between previously used immunological assays for serum vitamin $\mathrm{D}$, large-scale cross-sectional analysis has not been able to be reliably performed. The

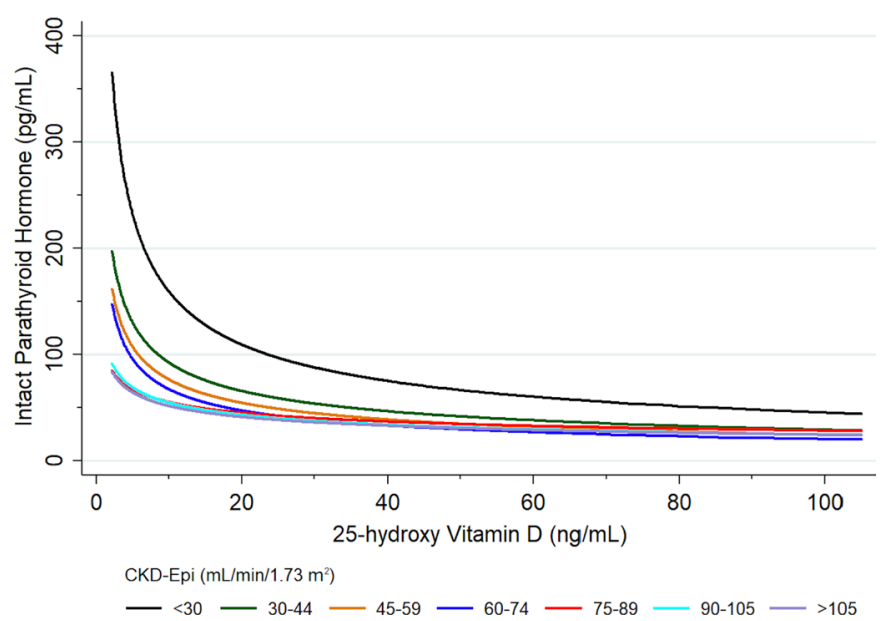

Figure 3 Non-linear regression of serum 25OHD to serum intact parathyroid hormone concentrations by kidney function in $15 \mathrm{~mL} / \mathrm{min} / 1.73 \mathrm{~m}^{2}$ increments. CKD-Epi, Chronic Kidney Disease-Epidemiology Collaboration estimation formula for glomerular filtration rate. present study used normalised data derived from the large cohort of NHANES participants collected from 2001 to 2012. During these years, the 25OHD status of US adults was measured by LC-MS/MS (either prospectively or retrospectively). The data presented here represent the 25OHD status of the US non-pregnant adult population determined by this gold standard assay methodology for vitamin D. Prior issues with assay performance have influenced the ability to determine vitamin $\mathrm{D}$ status due to immunoassay instability, variability in the assay types used across studies and performance of vitamin D assays under special circumstances. ${ }^{242728}$ To our knowledge, the current study represents the first attempt to report these data across all levels of kidney function using the gold standard assay.

The present study confirms previous reports of a low prevalence of vitamin D sufficiency, when sufficiency is defined as $>30 \mathrm{ng} / \mathrm{mL}$, both in the general population and advanced kidney dysfunction. ${ }^{4}{ }^{14}$ Despite the high prevalence of vitamin D insufficiency and deficiency, less than $40 \%$ of participants in the current study were taking vitamin D supplements. Even in those participants taking vitamin D supplements, the majority did not reach a $25 \mathrm{OHD}>30 \mathrm{ng} / \mathrm{mL}$, suggesting that improved supplemental vitamin $\mathrm{D}$ dosing strategies may be necessary to increase sufficiency.

In contrast to the variation of $25 \mathrm{OHD}$ with worsening kidney function noted in prior studies, ${ }^{14} 15$ and similar to cohort studies of kidney disease, ${ }^{16}{ }^{36}$ this analysis did not demonstrate a correlation of 25OHD deficiency with kidney function. Instead, a mild inverted U-shape was observed. In fact, only $19.9 \%$ of participants with eGFR $>105 \mathrm{~mL} / \mathrm{min} / 1.73 \mathrm{~m}^{2}$ were vitamin $\mathrm{D}$ sufficient, which was the lowest proportion of any of the kidney function groups examined. Similarly, only $31.9 \%$ of participants with the worst eGFR $\left(<30 \mathrm{~mL} / \mathrm{min} / 1.73 \mathrm{~m}^{2}\right)$ were vitamin D sufficient. In this lowest eGFR group, the lower proportion of vitamin $\mathrm{D}$ sufficiency may be explained by known increases in 24-hydroxylase related to elevated fibroblast growth factor (FGF)-23 ${ }^{13} 37$ that would lead to increased catabolism and elimination of vitamin $\mathrm{D}$. The low eGFR group also had the highest percent of lowest-income participants $(31.6 \%)$ and the highest percent with less than high school education (35.1\%), which might limit access to adequate diet and nutritional supplements. Perhaps contributing to the low prevalence of vitamin D sufficiency in participants with eGFR $>105 \mathrm{~mL} /$ $\min / 1.73 \mathrm{~m}^{2}$ may be the fact that fewer subjects in this group were taking supplemental vitamin D (only 27.1\%) in comparison to any other group. Factors contributing to low prevalence of vitamin D sufficiency in this group may be the highest percent women $(70.1 \%)$, younger age (mean age, 32.8 years) and the highest percent of non-Caucasians. Whereas vitamin $\mathrm{D}$ is an immune modulator and levels may be altered by inflammation (eg, an increased presence of FGF-23 activates 24-hydroxylase, thereby increasing the elimination of vitamin $\mathrm{D}^{37}$; or $1,25(\mathrm{OH})_{2} \mathrm{D}$ may suppress inflammation (interleukin (IL)-2) and 
promote anti-inflammatory cytokines (IL-10) ${ }^{38}$ ), it is not possible to explain the lower concentration of $25 \mathrm{OHD}$ in this highest eGFR group since FGF-23 or other markers of inflammation or anti-inflammatory markers were not available to evaluate.

An important observation in this study is the progressive increase in serum iPTH with decreasing 25OHD. This phenomenon was observed at each strata of kidney function, from normal to severely impaired. Also interesting was the further augmentation in the elevation of iPTH with decreasing vitamin D levels as kidney function declined. Similar observations were reported by Taal et al in a substudy of the Renal Risk in Derby study ${ }^{39}$ Using the LC-MS/MS assay for 25OHD, investigators in this study reported an independent, negative relationship between vitamin D concentration and iPTH. In contrast to the present study, however, the population in the Taal report included only those with reduced kidney function. The reasonable conclusion is that 25OHD concentration must always be considered when evaluating iPTH in patients with impaired kidney function and people with normal kidney function. Furthermore, both iPTH and $\mathrm{BAP}$ are biomarkers of bone resorption and negatively correlate with vitamin $\mathrm{D}$ concentration. In the current study, a higher iPTH was demonstrated with a vitamin D concentration $<40 \mathrm{ng} / \mathrm{mL}$, regardless of kidney function level. This suggests possible bone resorption occurring at vitamin $\mathrm{D}$ concentrations within the range advocated by the NAM as being consistent with bone health. These early biomarkers of bone health (iPTH and BAP) offer further indication that a higher than currently recommended vitamin $\mathrm{D}$ concentration may be warranted.

Sources and methods of exposure to vitamin D are multifactorial. Using serum 25OHD concentration as a biomarker of vitamin D status has some benefit over reliance on dietary intake estimates. Similar to therapeutic drug monitoring, assessing blood levels has been used to indicate biological processes. Assignment of cut points to categorise sufficiency of the vitamin has recently gained attention as a biomarker of the pathogenic process of bone diseases in both children and adults and has also been associated with increased risks for several immune-related diseases and cardiovascular disease. ${ }^{79}{ }^{11}$ However, determining the cut points for sufficiency is controversial with national guidelines based on preventing bone adverse outcomes. ${ }^{533}$ NAM has indicated that a $25 \mathrm{OHD}$ concentration $12-16 \mathrm{ng} / \mathrm{mL}$ is sufficient for half of the healthy US population and that $>20 \mathrm{ng} / \mathrm{mL}$ appears to offer no additional benefit for bone health. ${ }^{5}$ Using an endpoint of bone health outcomes (calcium absorption, bone mineral density, osteomalacia, rickets) on which to base their assessment may be appropriate for the general population. However, the current data indicate a relationship between 25OHD and iPTH that varied by kidney function strata, particularly at kidney function $<75 \mathrm{~mL} /$ $\mathrm{min} / 1.73 \mathrm{~m}^{2}$ despite having no differences in the proportion of people with obesity in the kidney function level groups. Moreover, the higher iPTH observed at levels of
$25 \mathrm{OHD}$ below $40 \mathrm{ng} / \mathrm{mL}$ at each kidney function strata suggests that a value $>30 \mathrm{ng} / \mathrm{mL}$ may be more optimal. As kidney disease $\left(\mathrm{eGFR}<60 \mathrm{~mL} / \mathrm{min} / 1.73 \mathrm{~m}^{2}\right)$ is present in approximately $14 \%$ of the US population, ${ }^{40}$ and more than half of US non-pregnant adults have kidney function $<90 \mathrm{~mL} / \mathrm{min} / 1.73 \mathrm{~m}^{2}$, closer accounting of kidney function and iPTH may be beneficial in assessment of the vitamin $\mathrm{D}$ status in adults with both normal or reduced kidney function.

The concentration of 25OHD (calcifediol) is approximately 1000 -fold that of $1,25(\mathrm{OH})_{2} \mathrm{D}$ (calcitriol, the bioactive metabolite) and has a longer circulating half-life: days to weeks versus hours. Thus, assessing the vitamin D status in the general population based on concentration of $25 \mathrm{OHD}$ is more feasible and is the biomarker selected by NHANES. However, since $1,25(\mathrm{OH})_{2} \mathrm{D}$ is also dependent on physiological functions (eg, decreased synthesis of 7-dehydrocholesterol in skin, decreased circulating 25OHD, decreased renal functional mass, increased FGF-23), it cannot be assumed that 25OHD concentrations directly correlate with $1,25(\mathrm{OH})_{2} \mathrm{D}$ concentrations. Regardless, a critical issue in understanding the implications of a deficient $25 \mathrm{OHD}$ concentration must include the downstream effect of such a deficiency on the concentration of $1,25(\mathrm{OH})_{2} \mathrm{D}$.

The non-skeletal related functions of vitamin D should also be addressed in relationship to levels of kidney function. For example, inflammation may provoke an increase in factors, such as FGF-23, ${ }^{37}$ that activate the degradation of vitamin $\mathrm{D}$ and, thereby, contribute to lower vitamin D concentration. Increased inflammation and decreased immune response often accompany decreased kidney function. ${ }^{41}{ }^{42}$ Furthermore, one of the hallmarks of kidney dysfunction, hypertension, has been shown to have a relationship with vitamin D concentration wherein randomised, placebo-controlled trials demonstrated reductions in systolic blood pressure with vitamin D supplementation. ${ }^{35} 4344$ Similarly, raising the 25OHD concentration through ultraviolet B exposure has also demonstrated a reduction in systolic blood pressure. ${ }^{45}$ These studies suggest additional reasons to maintain higher levels of vitamin D. Whereas a therapeutic dose of vitamin $\mathrm{D}$ that would be most beneficial has not been established for these conditions, recommendations for levels $>30 \mathrm{ng} / \mathrm{mL}$ have been suggested. ${ }^{10}$ The vitamin D level considered to be normal for the general population may not be sufficient if additional functions of vitamin D (eg, non-skeletal vs skeletal) are to be considered. Even in participants with the best kidney function, this study demonstrated that iPTH negatively associated with vitamin $\mathrm{D}$ concentration.

The cross-sectional design of this study limits the ability to infer causation and we are unable to test the role that other compounds (eg, FGF-23 and 24-hydroxylase or the measurement of $\left.1,25(\mathrm{OH})_{2} \mathrm{D}\right)$ or environmental conditions contribute to the 25OHD and iPTH concentrations observed. Whereas participants were assessed at the time of year when sun exposure was lowest in the Southern 
USA and highest in the Northern USA, an approach by NHANES to normalise the level of vitamin D exposure represented by the participants, it is still possible that usual vitamin $\mathrm{D}$ levels were not demonstrated in this cross-sectional study. Another consideration is that while NHANES performs a very thorough study of participants' health, it is not possible to measure every factor of interest; assessment of vitamin D receptor activity would perhaps provide greater insight into the associations seen in this study. Additionally, the single-point serum creatinine in NHANES does not allow for assigning chronicity (or stages) to the kidney function level ${ }^{32}$ which limits the opportunity to confirm that the findings reflect steadystate metabolism or would endure longitudinally. We did not assess the total dietary intake of vitamin $\mathrm{D}$ in this cohort because the nutrient data tables did not include dietary vitamin D in 2001-2006. Further evaluation of dietary vitamin $\mathrm{D}$ intake in the kidney function level groups is recommended.

The mechanisms influencing 25OHD and iPTH concentrations are complex and the current study further corroborates the complexity. Research incorporating prospective longitudinal studies could improve our understanding of these phenomena and should account for both kidney function and vitamin D status and should use international standards and accurate assays when assessing $25 \mathrm{OHD}$ concentration.

\section{CONCLUSIONS}

25OHD concentration should be measured, using accurate assay methodology, when assessing iPTH or other early biomarkers of bone health, and account for kidney function level. Vitamin D supplementation results in increased 25OHD concentrations at each level of kidney function. Optimal 25OHD concentrations are associated with lower iPTH concentration at all levels of kidney function. Together, these data support a re-evaluation of the range of 25OHD concentration associated with health in the US non-pregnant adult population.

Acknowledgements The authors wish to posthumously acknowledge the inspirational and intellectual contributions of Dr Sherilyn Gordon Burroughs in the preparation of this manuscript. Acknowledgement is made to Duc T Nguyen, $\mathrm{MD}, \mathrm{PhD}$, and Edward A Graviss, PhD, for their contributions to figure 3 and its statistic. We also acknowledge the considerable contribution of the participants and designers of the National Health and Nutrition Examination Survey that makes this work possible.

Contributors LWM and WNS designed research; LWM conducted research, performed statistical analysis and had primary responsibility for final content; LWM, WNS, KEL, OMS, RJK and AOG wrote the paper. All authors have read and approved the final manuscript.

Funding This work was supported by Renal Research, Inc.; no grant number.

Disclaimer The funders had no involvement in the study design, collection, analysis or interpretation of the data; in the writing of the report; or in the decision to submit the paper for publication.

Competing interests None declared.

Patient consent for publication Not required.

Ethics approval The National Center for Health Services Research Ethical Review Board of the United States Department of Health and Human Services.
Provenance and peer review Not commissioned; externally peer reviewed.

Data sharing statement No additional data are available from the authors. The data set used for this study was compiled from public use files accessible to anyone from the US Centers for Disease Control and Prevention at https://www.cdc. gov/nchs/nhanes/.

Open access This is an open access article distributed in accordance with the Creative Commons Attribution Non Commercial (CC BY-NC 4.0) license, which permits others to distribute, remix, adapt, build upon this work non-commercially, and license their derivative works on different terms, provided the original work is properly cited, appropriate credit is given, any changes made indicated, and the use is non-commercial. See: http://creativecommons.org/licenses/by-nc/4.0/.

\section{REFERENCES}

1. van Schoor NM, Lips P. Worldwide vitamin D status. Best Pract Res Clin Endocrinol Metab 2011;25:671-80.

2. Hilger J, Friedel A, Herr R, et al. A systematic review of vitamin D status in populations worldwide. Br J Nutr 2014;111:23-45.

3. Cashman KD, Dowling KG, Škrabáková Z, et al. Vitamin D deficiency in Europe: pandemic? Am J Clin Nutr 2016;103:1033-44.

4. Looker AC, Dawson-Hughes B, Calvo MS, et al. Serum 25-hydroxyvitamin D status of adolescents and adults in two seasonal subpopulations from NHANES III. Bone 2002;30:771-7.

5. IOM [Institute of Medicine]. Dietary reference intakes for calcium and Vitamin D. Washington, DC: The National Academies Press, 2011.

6. Manson JE, Brannon PM, Rosen CJ, et al. Vitamin D Deficiency - Is There Really a Pandemic? N Engl J Med 2016;375:1817-20.

7. Jones G, Vitamin D. et alln: Ross AC, Caballero B, Cousins RJ, Tucker KL, Ziegler TR, Williams L, . Modern nutrition in health and disease. 11th ed. Philadelphia: PA, 2014:278-92.

8. Bouillon R. Why modest but widespread improvement of the vitamin D status is the best strategy? Best Pract Res Clin Endocrinol Metab 2011;25:693-702.

9. Holick MF. Vitamin D deficiency. N Engl J Med Overseas Ed 2007;357:266-81.

10. Holick MF, Binkley NC, Bischoff-Ferrari HA, et al. Evaluation, treatment, and prevention of vitamin $D$ deficiency: an endocrine society clinical practice guideline. J Clin Endocrinol Metab 2011;96:1911-30.

11. Dankers W, Colin EM, van Hamburg JP, et al. Vitamin D in autoimmunity: molecular mechanisms and therapeutic potential. Front Immunol 2016;7

12. Mirhosseini N, Vatanparast $\mathrm{H}$, Mazidi M, et al. The effect of improved serum 25-Hydroxyvitamin D Status on glycemic control in diabetic patients: a meta-analysis. J Clin Endocrinol Metab 2017;102:3097-110.

13. Dusso A, González EA, Martin KJ. Vitamin D in chronic kidney disease. Best Pract Res Clin Endocrinol Metab 2011;25:647-55.

14. LaClair RE, Hellman RN, Karp SL, et al. Prevalence of calcidiol deficiency in CKD: a cross-sectional study across latitudes in the United States. Am J Kidney Dis 2005;45:1026-33.

15. Park J, Ryu SY, Han MA, et al. The Association of Vitamin D With estimated glomerular filtration rate and albuminuria: 5th korean national health and nutritional examination survey 2011-2012. J Ren Nutr 2016;26:360-6.

16. Levin A, Bakris GL, Molitch M, et al. Prevalence of abnormal serum vitamin D, PTH, calcium, and phosphorus in patients with chronic kidney disease: results of the study to evaluate early kidney disease. Kidney Int 2007;71:31-8.

17. Halloran BP, Schaefer P, Lifschitz M, et al. Plasma vitamin D metabolite concentrations in chronic renal failure: effect of oral administration of 25-hydroxyvitamin D3. J Clin Endocrinol Metab 1984;59:1063-9.

18. Dusso AS, Tokumoto M. Defective renal maintenance of the vitamin $D$ endocrine system impairs vitamin D renoprotection: a downward spiral in kidney disease. Kidney Int 2011;79:715-29.

19. Zierold C, Martin KJ, DeLuca HF. Vitamin D metabolism in normal and chronic kidney disease states. In: Urefia Torres PA, Vervloet MG, Cozzolino M, eds. Vitamin D in chronic kidney disease. Switzerland: Springer International Publishing, 2016:3-17.

20. Wortsman J, Matsuoka LY, Chen TC, et al. Decreased bioavailability of vitamin D in obesity. Am J Clin Nutr 2000;72:690-3.

21. Blum M, Dolnikowski G, Seyoum E, et al. Vitamin $D(3)$ in fat tissue. Endocrine 2008;33:90-4.

22. Drincic AT, Armas LA, Van Diest EE, et al. Volumetric dilution, rather than sequestration best explains the low vitamin $D$ status of obesity. Obesity 2012;20:1444-8. 
23. Flegal KM, Carroll MD, Kit BK, et al. Prevalence of obesity and trends in the distribution of body mass index among US adults, 1999-2010. JAMA 2012;307:491-7.

24. Cavalier E, Delanaye P. Measurement of circulating 1,25-dihydroxyvitamin $D$ and vitamin $D$-binding protein in chronic kidney disease. In: Urefia Torres PA, Vervloet MG, Cozzolino M, eds. Vitamin D in Chronic kidney disease. Switzerland: Springer International Publishing, 2016:117-28.

25. Nielson CM, Jones KS, Bouillon R, et al. Role of assay type in determining free 25-Hydroxyvitamin $D$ Levels in diverse populations. N Engl J Med 2016;374:1695-6.

26. Powe CE, Evans MK, Wenger J, et al. Vitamin D-binding protein and vitamin D status of black Americans and white Americans. $N$ Engl J Med 2013;369:1991-2000.

27. Yetley EA, Pfeiffer CM, Schleicher RL, et al. NHANES monitoring of serum 25-hydroxyvitamin D: a roundtable summary. J Nutr 2010;140:2030S-45.

28. Schleicher RL, Sternberg MR, Lacher DA, et al. A method-bridging study for serum 25-hydroxyvitamin d to standardize historical radioimmunoassay data to liquid chromatography-tandem mass spectrometry. national health statistics reports; no. 93. Hyattsville, MD: National Center for Health Statistics, 2016.

29. Laboratory Procedure Manual, NHANES 2005-2006; Parathyroid Hormone. National health and nutrition examination survey. 2008 https://wwwn.cdc.gov/nchs/data/nhanes/2005-2006/labmethods/ pth d met parathyroid_hormone.pdf

30. Laboratory Procedure Manual, NHANES 2003-2004; Bone Alkaline Phosphatase. National health and nutrition examination survey. 2004 https://wwwn.cdc.gov/nchs/data/nhanes/2003-2004/labmethods/ I11_c_met_bap.pdf

31. Levey AS, Stevens LA, Schmid $\mathrm{CH}$, et al. A new equation to estimate glomerular filtration rate. Ann Intern Med 2009;150:604-12.

32. Kidney Disease: Improving Global Outcomes Workgroup. KDIGO 2012 clinical practice guideline for the evaluation and management of chronic kidney disease. Kidney Int Suppl 2013;3:i-150.

33. Bischoff-Ferrari HA, Giovannucci E, Willett WC, et al. Estimation of optimal serum concentrations of 25-hydroxyvitamin D for multiple health outcomes. Am J Clin Nutr 2006;84:18-28.
34. Johnson CL, Paulose-Ram R, Ogden CL, et al. National health and nutrition examination survey: analytic guidelines, 1999-2010. Vital Health Stat 2 2013:1-24.

35. Pfeifer M, Begerow B, Minne HW, et al. Effects of a short-term vitamin $\mathrm{D}(3)$ and calcium supplementation on blood pressure and parathyroid hormone levels in elderly women. J Clin Endocrinol Metab 2001;86:1633-7.

36. Rebholz CM, Grams ME, Lutsey PL, et al. Biomarkers of Vitamin D Status and Risk of ESRD. Am J Kidney Dis 2016;67:235-42.

37. Shimada T, Hasegawa H, Yamazaki Y, et al. FGF-23 is a potent regulator of vitamin $\mathrm{D}$ metabolism and phosphate homeostasis. $J$ Bone Miner Res 2004;19:429-35.

38. Barker T, Martins TB, Hill HR, et al. Circulating pro-inflammatory cytokines are elevated and peak power output correlates with 25-hydroxyvitamin D in vitamin D insufficient adults. Eur J Appl Physiol 2013;113:1523-34.

39. Taal MW, Thurston V, Mclntyre NJ, et al. The impact of vitamin D status on the relative increase in fibroblast growth factor 23 and parathyroid hormone in chronic kidney disease. Kidney Int 2014;86:407-13.

40. U.S. Renal Data System. 2016 https://www.usrds.org/adr.aspx (Accessed16 Feb 2018).

41. Carrero JJ, Stenvinkel P. Persistent inflammation as a catalyst for other risk factors in chronic kidney disease: a hypothesis proposal. Clin J Am Soc Nephrol 2009;4 :S49-55.

42. Isakova T, Gutiérrez OM, Patel NM, et al. Vitamin D deficiency, inflammation, and albuminuria in chronic kidney disease: complex interactions. J Ren Nutr 2011;21:295-302.

43. Giannini S, Mazzaferro S, Minisola S, et al. Raising awareness on the therapeutic role of cholecalciferol in CKD: a multidisciplinary-based opinion. Endocrine 2018;59:242-59.

44. Forman JP, Scott JB, Ng K, et al. Effect of vitamin D supplementation on blood pressure in blacks. Hypertension 2013;61:779-85.

45. Krause R, Stange R, Roth HJ, et al. Partial Body UV Exposure in chronic kidney disease and extrarenal Vitamin D metabolism. Anticancer Res 2018;38:1217-9. 